\title{
Nutrition research priorities for the United Kingdom
}

\section{By Sir Kenneth Blaxter, Rowett Research Institute, Bucksburn, Aberdeen $A B 2$ $9 S B$}

In 1971 Lord Rothschild made certain proposals about how decisions should be taken when public funds are to be used to support research and development. He stated 'However distinguished, intelligent and practical scientists may be they cannot be so well qualified to decide what the needs of the nation are and their priorities as those responsible for ensuring that those needs are met'. He proposed (Cmnd 4814) that the applied research and development financed by Government should accord with the customer-contractor principle which he epitomized in the statement 'The customer says what he wants, the contractor does it if he can; and the customer pays'. The customers were identified as the departments of Government, these being in most instances regarded as representing the interests of the population as a whole. The principle was adopted by Government in its White Paper of 1972 (Cmnd 5046).

In the years that have followed the acceptance of the principle it has become obvious that Government departments have encountered difficulty in formulating what research and development they require. It could be argued that Lord Rothschild was wrong to regard them as better qualified to judge the needs of the nation and their priorities than scientists. Alternatively, it could be argued that they have realized the desirability of attaining a wide consensus about what is important and what is not. Certainly a series of structures to provide information about research that needs to be done and to assign priorities to particular items has been set up to advise departments, and in these structures many people with very diverse interests have been involved. Consultation has been very wide. The Joint Consultative Organisation for Research and Development in Agriculture and Food (MAFF, I977), for example, currently has more than 440 people sitting on its various Boards and Committees. This is quite apart from its Working Parties and excludes the necessary representation on each group by the contracting parties. Similar wide consultation has taken place in other fields which relate to food and nutrition, notably those related to health and environmental considerations. One can in fact conclude that never before has there been so much discussion about what research should be done and what priorities should be accorded to each specific item. Growth of this decision-making machinery and the parallel machinery to review what has been accomplished and at what cost has been far greater than the growth of the operational sector which actually undertakes research work, indeed the latter has declined. Even so, it must be pointed out that research scientists are well represented in these planning and decision-making processes and have, in most instances, been the primary source of ideas. This was 
indeed recognized in the White Paper in an explicit statement. The black and white distinction made by Lord Rothschild between scientists on the one hand and those who are concerned with the social and political implications of research and development and with decision on the other does not apply.

In these circumstances, with such a vast effort devoted to the assigning of priorities in the various fields of knowledge which involve nutrition, it hardly seems sensible for an individual to give his own list of priorities. These could only be a reiteration of what has been discussed at length elsewhere with a change of emphasis reflecting personal views. Accordingly, I wish to discuss certain problems of a wider nature which relate to the assigning of priority, and the implications of priority designations.

The Joint Committee of the Agricultural and Medical Research Councils on Food and Nutrition Research was established in 1970 with Professor Neuberger as its Chairman, that is before the Government had formulated its new science policy. Although its report was published in 1974, much of its work had been done before 1972. It recommended what it thought research priorities should be in the whole field of human nutrition in a short chapter of three pages and these recommendations were very simple. Work needed to be done which related firstly to the safety and quality of the food supply, secondly to the elucidation of the role of nutrition in the aetiology of diseases of complex or uncertain aetiology and thirdly to the extension of fundamental knowledge of nutrition so to be better able to understand nutritional problems in the future. Each of these three divisions was regarded as of equal importance, that is required equal priority. I think this balance of priority rating is about right, and particularly that fundamental study should constitute about a third of the total expenditure of effort and of wealth. The first two divisions concerned with obvious problems are readily encompassea by the concept of applied research and development; the third is not and is greater than the $10 \%$ which Lord Rothschild thought a sufficient proportion for speculative research. Professor Neuberger's Committee discussed in this short chapter under each heading certain problems which it regarded as important or urgent, calling attention inter alia to possible nutritional causes of vascular disease, cancer and obesity, to factors affecting food habits, to the socio-economic implications of dietary practices and to the microbiology of food. These were largely illustrative of the three main priority areas, though some specific topics were given considerable emphasis but without indication of the relative weight to be given to them.

Following consideration of the 'Neuberger Report' the two research councils and Government departments issued joint policy statements. The policy statement by the Medical Research Council and the Health Departments (1977) also designated areas they thought demanded priority. Four such areas were designated; two, those related to nutritional surveillance and to food quality and safety accord with the first recommendation of the Neuberger Report, while the remaining two comprise the same areas covered by the remaining two of the 1974 report. The research council and health departments thus singled out one area concerned with the extension of knowledge rather than with an immediate practical problem. 
The broad designation of priority areas in both the Neuberger Report and the policy statements, however, have shortcomings. They do not say anything at all about what level of support should be given to nutrition as a whole relative to other branches of biological science or to the physical and social sciences. Neither do they give very much guidance about what priority should be given within each of the large areas they designated and in part expanded. How much research should be done on nutritional aspects of obesity relative to investigations pertinent to the role of nutritional factors in cardiovascular disease? And if obesity is to be given some priority, how much should be given to, for example, each of the five aspects which the Joint Working Group on Obesity, set up by the Committee on Medical Aspects of Food Policy (Department of Health and Social Security \& Medical Research Council 1976), thought demanded immediate attention? Should epidemiological studies on the prevalence of obesity in children enjoy a greater priority than research on the role of thermogenesis in energy regulation?

These criticisms of what are in fact the policy statements by both the Neuberger Committee and by the MRC and the Health Departments imply that there must be other assessments of the relative importance of research in different fields, some at higher levels some at lower ones, than those concerned with the broad assignments of priority in policy terms. The over-all funding of food and nutrition research competes with other work in medicine and agriculture; medical and agricultural research compete with research in other sciences. There is no fixed or immutable proportion of some hypothetical research cake to be allotted to food and nutrition. Rather there is a changing support dependent on the assessment of the relative likely benefit to be obtained constrained by the inertia associated with the institutional framework of the subject built up by past success. Currently, for example, research on alternative energy sources and on the sociological issues raised by our increased urbanization attracts considerable support from public and private funds because the cases for likely future benefit have become obvious to all. Similarly, it is doubtful whether research expenditure on molecular biology could be reduced very quickly (if indeed it should be) because the subject has become institutionalized through past investment in it.

At the operational level, the provision of funds whether public ones or those associated with other bodies are primarily judged on their scientific merit, and it could be argued that there is no need for a detailed priority rating to be given and that a general policy statement is sufficient guidance. The merit assessment inevitably involves consideration of the work in the context of international science; priorities may well be accorded within a national context but work is judged within an international frame.

This immediately raises a series of questions about the whole concept of priority in relation to the growth of knowledge of nutrition, its applied aspects and its practical implementation. If priority is given to some areas, then other areas are given none. Priority assignment could be regarded not so much as a rationalizing of the distribution of effort or of encouraging growth of interest, but as a process of opting out of certain fields of endeavour and leaving them to be cultivated by 
others. Indeed, in the Neuberger Report it is stated that repetition of costly and extensive dietary trials related to the possible nutritional causes of vascular disease should not be encouraged. The critical aspect is really what to do about a priority listing once this has been devised; if it involves a concentration of resources within a few defined areas then when new problems arise the technical expertise may not be available to deal with them; if it involves an encouragement of able people to enter new areas, other areas may be neglected; if it involves an expansion of the over-all commitment, then considerations of cost loom large. Again, if an area is singled out for priority treatment then this might well encourage poor quality work if there is little interest in the problem by highly gifted and motivated people. It is very easy to arrive at a consensus about what work should be done, more difficult to place such proposals in a priority order but very difficult indeed to implement the resultant programme for the latter has implications far removed from the initial considerations.

There is no shortage of nutritional problems of importance in terms of their possible implications on the health and well-being of the public, in terms of their general interest or in terms of the intellectual challenge they present. Some are daunting in that they defy the classical experimental approach, examples being those which relate disease in later life to early nutrition. Others call for close collaboration with those in other disciplines, examples being nutrition in relation to immune mechanisms and to mental development. Still others relate to the behavioural sciences and to economics where entirely novel approaches are required. Indeed, there is a real difficulty at present in defining in any precise way what constitutes the field of endeavour in nutrition let alone priorities within it for there is a nutritional component in virtually every branch of human biology and medicine. Formerly this was clearly not thought to be so; it was thought that nutrition could be identified. Thus, in the letters of invitation from the research councils inviting members to serve on Professor Neuberger's Committee, this sentence appears: 'With the discovery of what might be considered a complete list of vitamins, the identification of the essential amino acids and trace metals and the partial success which has been achieved in defining quantitative requirements for various nutrients in man, research in nutrition has at least to some extent achieved its original goal'. This suggests that there was a view in 1970 that the research era of nutrition was nearing completion and that all that was required was a mopping up operation to define requirements of known nutrients more precisely. It can, of course, be pointed out that the list of known essential nutrients has been increased since 1970; Vanadium, nickel, tin and silicon are essential and carnitine is depleted in the bodies of patients undergoing complete parenteral feeding. Such quibbling, however, does not indicate that to regard nutrition simply as a search for nutrients is to take a very limited view. Happily the emphasis given in the Neuberger Report and in the policy statements suggests that this limited view no longer applies.

The Neuberger Report in its delineation of three priority areas has in effect redefined the province of nutrition. Firstly, it recognizes that we now can define 'at least to some extent' man's nutrient needs and so can assess dietary adequacy. A 
continuous process of investigation is called for in which at all times it is realized that changes in the technology of food provision and in social structures can induce changes in nutritional status. I am quite certain that when new problems are uncovered in this area then there will be the scientific capability to investigate more deeply and priority accorded in terms of the necessary funds and facilities to enable this to be done. Secondly, it recognizes that nutrition may be involved in illness and disease and contribute to morbidity and mortality in ways other than those associated with gross deficiency of essential nutrients. Such recognition appreciates the cost of illness to the community; if, for example, improved nutrition of the elderly curtails their hospitalization in later years, then the benefit to all is considerable. It might be said that it is perhaps more important to establish firmly and unequivocally a link between nutrition and morbidity than to argue about which disease entity within this category should have the highest priority. Thirdly, the Report recognizes that there must be a continuous investment in fundamental work. Several suggestions were made about areas likely to be productive, but the whole of the technical report was adduced to indicate the range of possibility. Priority assignments here are more difficult; they involve a considerable amount of guesswork about the probability of success and indeed about the probability that entirely unsuspected things might be discovered. Perhaps the only criterion to be adopted is the older one based on an appreciation of the ability of those who wish to undertake the work. Nevertheless, and as I mentioned earlier, a third of our total effort should be devoted to this area. The Report thus redefines nutritional research in terms of the discovery of problems, the solving of known or suspected problems and the provision of a base of new knowledge to enable them to be solved.

In conclusion, it is evident from my remarks that $I$ believe that there is an immense amount of useful work to be done in the large field of food and nutrition and that the policy adumbrated in the Neuberger Report and since confirmed by the Research Councils and Health Departments has gone a long way towards redefining the area of our competence. There are difficulties in assigning priority and greater ones in implementing them; there are difficulties in providing the funds which are necessary because nutrition research competes with other activities both for public and private support. What priorities are accorded to nutritional research in future will depend on the extent to which we demonstrate its importance and the role which it does, and can, play in safeguarding and improving the well-being of the community as a whole.

\section{REFERENCES}

Agricultural Research Council and Medical Research Council (1974). Food and Nutrition Research. London: HM Stationery Office.

Cmnd $48 \mathrm{I}_{4}$ (1971). A Framework for Government Research and Development. London: HM Stationery Office.

Cmnd 5046 (1972). A Framework for Government Research and Development. London: HM Stationery Office.

Department of Health \& Social Security and Medical Research Council (1976). Research on Obesity. London: HM Stationery Office. 
Ministry of Agriculture, Fisheries and Food (1977). Reports of the Boards of the foint Consultative Organisation for Research and Development in Agriculture and Food, 1976-77. London: HM Stationery Office. 